Research Paper

\title{
Inflammatory Response and Toxicity After Pressurized IntraPeritoneal Aerosol Chemotherapy
}

\author{
Hugo Teixeira Farinha*, Fabian Grass ${ }^{*}$, Ismaïl Labgaa, Basile Pache, Nicolas Demartines ${ }^{\bowtie}$, Martin Hübner \\ Department of Visceral Surgery, University Hospital of Lausanne (CHUV), Switzerland. \\ * equal contribution \\ $\triangle$ Corresponding author: Nicolas Demartines, Department of Visceral Surgery, Lausanne University Hospital CHUV, 1011 Lausanne, Switzerland. Phone : +41 \\ 2131424 00; Fax : +41 2131424 11; E-mail : martin.hubner@chuv.ch \\ (C) Ivyspring International Publisher. This is an open access article distributed under the terms of the Creative Commons Attribution (CC BY-NC) license \\ (https://creativecommons.org/licenses/by-nc/4.0/). See http://ivyspring.com/terms for full terms and conditions.
}

Received: 2017.06.04; Accepted: 2017.10.08; Published: 2018.01.01

\begin{abstract}
Background: Pressurized Intraperitoneal Aerosol Chemotherapy (PIPAC) is a novel mode of intraperitoneal (IP) drug delivery claiming high IP tissue concentrations with low systemic uptake. The aim was to study inflammatory response and systemic toxicity after PIPAC.

Methods: Retrospective monocentric analysis of a consecutive cohort of PIPAC patients between January 2015 and April 2016. Detailed hematological and biochemical analysis was performed the day before surgery and once daily until discharge. Comparative statistics were performed using Mann-Whitney $U$ test and Wilcoxon signed ranked test.

Results: Fourty-two consecutive patients underwent a total of 91 PIPAC procedures. Twenty patients received oxaliplatin and 22 cisplatin+doxorubicin ( 37 vs. 54 procedures). Creatinine, AST and ALT were not significantly altered after PIPAC $(p=0.095, p=p=0.153$ and $p=0.351)$ and not different between oxaliplatin and cisplatin+doxorubicin regimens $(p=0.371, p=0.251$ and $p=0.288)$. C-reactive protein (CRP) and procalcitonin (PCT) increased on post-operative day (POD) 2: $\Delta$ max $29 \pm 5 \mathrm{mg} / \mathrm{L}(p<0.001)$ and $\Delta \max 0.05 \pm 0.01 \mu g / L(p=0.005)$, respectively. Leucocytes increased at POD 1: $\Delta \max 2.2 \pm 0.3 \mathrm{G} / \mathrm{L}(\mathrm{p}<0.001)$. Albumin decreased at POD 2: $\Delta \max -6.0 \pm 0.5 \mathrm{~g} / \mathrm{L}(\mathrm{p}<0.001)$. CRP increase correlated positively with Peritoneal Cancer Index (tumor load) $(\rho=0.521, p<0.001)$.

Conclusion: PIPAC was followed by a modest and transitory inflammatory response that was commensurate to the disease extent. No hematological, renal or hepatic toxicity was observed even after repetitive administration.
\end{abstract}

Key words: PIPAC, Peritoneal Carcinomatosis, Toxicity, Intraperitoneal Chemotherapy

\section{Introduction}

Intraperitoneal (IP) chemotherapy is a treatment alternative for selected patients with peritoneal carcinomatosis (PC) [1, 2]. The rationale for IP treatment is to obtain higher intraperitoneal concentrations with low systemic uptake to reduce systemic toxicity [3, 4]. Intraabdominal complications, hematological but also renal toxicity, and a profound inflammatory response are typical adverse events of both types of conventional treatment, namely hyperthermic IP chemotherapy by lavage (HIPEC) and IP chemotherapy administered by an implantable catheter [5-7].

Pressurized Intraperitoneal Aerosol Chemotherapy (PIPAC) is a novel minimal-invasive approach for intraperitoneal drug delivery. Administration as an aerosol allows for better distribution within the abdominal cavity, and tissue concentrations of the therapeutic agents are increased 
under pressure conditions (pneumoperitoneum) despite lower concentrations than for conventional intraperitoneal chemotherapy [1].

The aim of this study was to assess hematological, renal and hepatic toxicity in a consecutive cohort of PIPAC patients and to measure inflammatory response after PIPAC.

\section{Methods}

PIPAC was introduced at the University Hospital of Lausanne (CHUV) in January 2015. All patients entered a prospectively maintained coded online data base. Considered for PIPAC treatment were patients with isolated PC of various origins with persistence or progression after standard treatment including surgery and systemic chemotherapy $(\geq 2$ lines for most patients). All indications were confirmed during multidisciplinary tumor board. PIPAC treatment alone was preferred and combined intraperitoneal and systemic treatment was exceptional. The present analysis on toxicity and inflammatory response includes all consecutive patients operated until April 2016. Feasibility, postoperative outcomes and quality of life of this cohort were reported recently $[8,9]$. The study was approved by the Institutional Review Board $\left(\mathrm{N}^{\circ} 2016 / 0274\right)$ and all patients provided written consent for utilization of their data. This study was registered online (www.researchregistry.com \#UIN: 2197). STROBE criteria [10] were adhered to for conduction and reporting of the study. The study was conducted in accordance with the principles of the Declaration of Helsinki.

\section{PIPAC procedure and treatment algorithm}

Methodology and surgical approach of PIPAC have been reported elsewhere $[8,11]$. Briefly, three PIPAC treatments were scheduled at 6-week intervals upon decision of multidisciplinary tumor board. Every patient was seen in outpatient consultation 4 weeks after PIPAC treatment for monitoring of complications and evaluation of contraindications to proceed with PIPAC procedures. Thoraco-abdominal computed tomography (CT) was performed 4 weeks prior to first PIPAC and between PIPAC\#2 and PIPAC\#3 to rule out extraperitoneal disease and a third CT was scheduled 2 months after completion of 3 PIPAC treatments [8]. Intraperitoneal chemotherapy regimens were defined on individual basis adhering closely to the empiric definitions of the German pioneer group suggesting oxaliplatin monotherapy (92 $\mathrm{mg} / \mathrm{m}^{2}$ body surface) for colorectal primary and combined cisplatin $\left(7.5 \mathrm{mg} / \mathrm{m}^{2}\right.$ body surface) and doxorubicin $\left(1.5 \mathrm{mg} / \mathrm{m}^{2}\right.$ body surface) for ovarian and gastric origin $[8,11,12]$. IP treatment was administered for 30 minutes at $37^{\circ} \mathrm{C}$ and with a standard laparoscopic pressure of $12 \mathrm{mmHg}$. After treatment, pneumoperitoneum with potential remaining cytostatics was evacuated via a closed system including two microparticle filters [2].

\section{Assessment of postoperative toxicity and inflammation}

Blood drawings were performed in a fasting state following standardized institutional guidelines, the day before surgery and once daily until discharge.

Toxicity was assessed by measuring creatinine (Crea) $(\mu \mathrm{mol} / \mathrm{L})$, aspartate aminotransferase (AST, institutional reference (IR): $<50 \mathrm{U} / \mathrm{L}$ ) and alanine aminotransferase (ALT, IR: $<50 \mathrm{U} / \mathrm{L}$ ). Acute renal dysfunction was defined as post-treatment creatinine increase $>50 \%$ according to Risk, Injury, Failure, Loss of kidney function, and End stage kidney disease (RIFLE) and Acute Kidney Injury Network (AKIN) classification [13, 14].

Inflammatory response was assessed measuring leukocyte (Lc) counts (IR: 4.0-10.0 G/L), C-reactive protein (CRP, IR: $<5 \mathrm{~g} / \mathrm{L}$ ), procalcitonin (PCT, IR: $<0.06 \mu \mathrm{g} / \mathrm{L}$ ) and albumin (Alb, IR: 32-46 g/L). Maximal values were considered for Lc, CRP and PCT. Relevant postoperative inflammation was defined according to literature as Lc $>12 \mathrm{G} / \mathrm{L}$, CRP $>140 \mathrm{~g} / \mathrm{L}$ and PCT $>0.25 \mu \mathrm{g} / \mathrm{L}$ [15-17]. Maximal difference between the pre- and postoperative values was used for albumin $(\Delta \mathrm{Alb})$ and a cut-off value of $>10 \mathrm{~g} / \mathrm{L}$ was used to indicate important inflammatory response [18]. Temperature was measured 4 times per day during the hospitalization.

\section{Predefined clinical questions}

Several comparisons and statistical correlations were defined a priori: Evaluation of cumulative toxicity after repetitive PIPAC applications and comparison of systemic inflammation between PIPAC\#1, PIPAC\#2 and PIPAC\#3. Comparison of inflammation and toxicity response between patients treated with oxaliplatin $v$ s. cisplatin and doxorubicin. Correlation between tumor load as assessed by the Peritoneal Cancer Index (PCI) and post-inflammatory response [19].

\section{Statistical analysis}

Continuous variables were presented as mean with standard error of the mean (SEM) or median with range or interquartile range (IQR) for skewed data. Categorical variables were reported as frequencies (\%) and compared with chi-square test. Wilcoxon signed ranked test, Mann-Whitney test and Kruskal-Wallis test were used for statistical comparisons. Statistical correlations were tested by use of Pearson's rank correlation. All statistical tests 
were two-sided and a level of 0.05 was used to indicate statistical significance. Statistical analyses were performed and figures were produced with SPSS v20 statistical software (Chicago, IL, USA) and GraphPad Prism 7 (GraphPad Software, Inc., La Jolla, CA, USA).

\section{Results}

\section{Patients' characteristics and details of the procedures}

The present cohort included 42 consecutive patients who underwent a total of 91 PIPAC procedures, distributed in 2 groups receiving oxaliplatin vs. cisplatin+doxorubicin, respectively. The oxaliplatin group was composed of 20 patients (37 procedures) with colorectal primay (15), small bowel cancer and pseudomyxoma (1 each), and 3 patients with gastric cancer. For the latter group, medical oncologists decided on individual basis to deviate from the empirical protocol (twice due to contraindications). The remaining 22 patients (21 ovarian, 1 mesothelioma; 54 procedures) received cisplatin+doxorubicin according to recommendations. Baseline characteristics are displayed in Table 1.

Surgery typically required 2 trocars for a median duration of 94 (89-108) minutes, whereas median PCI was $10[8,9]$.

\section{Toxicity}

Creatinine level was not significantly altered after PIPAC procedures at post-operative day (POD) 2: $\Delta \max -3 \pm 1 \mu \mathrm{mol} / \mathrm{L} \quad(\mathrm{p}=0.095)$. Based on liver enzymes AST and ALT on POD 2, no hepatotoxicity was caused by PIPAC treatment: $\Delta \max -13 \pm 4 \mathrm{U} / \mathrm{L}$ $(p=0.153)$ and $\Delta \max 4 \pm 3 U / L(p=0.351)$ respectively. Differences in hepato-renal impact comparing the two regimens were not significant as detailed in Figure 1.
Likewise, no difference was noted when comparing consecutive PIPAC procedures for all three parameters (Figure 2).

Seven $(17 \%)$ and $6(14 \%)$ patients surpassed institutional thresholds for AST and ALT, respectively. There was no lasting effect. No patient presented acute kidney injury according to RIFLE criteria or AKIN classification.

Table 1. Baseline demographics of patients treated with Pressurized Intraperitoneal Aerosol Chemotherapy (PIPAC)

\begin{tabular}{llll}
\hline & $\begin{array}{l}\text { Overall } \\
(\mathrm{n}=42)\end{array}$ & $\begin{array}{l}\text { Oxaliplatin } \\
(\mathrm{n}=20)\end{array}$ & $\begin{array}{l}\text { Cisplatin +Doxorubicin } \\
(\mathrm{n}=22)\end{array}$ \\
\hline $\begin{array}{l}\text { Demographics } \\
\text { Age (years) }\end{array}$ & $66(59-73)$ & $62(53-73)$ & $68(63-75)$ \\
Gender $($ male $)(\%)$ & $8(19)$ & $8(40)$ & - \\
BMI $\left(\mathrm{kg} / \mathrm{m}^{2}\right)$ & $22.5(20-25)$ & $21.5(19-25)$ & $22.7(22-28)$ \\
Cancer origin & & & \\
Colorectal $(\%)$ & $15(36)$ & $15(75)$ & - \\
Gastric $(\%)$ & $3(7)$ & $3(15)$ & - \\
Ovarian $(\%)$ & $21(50)$ & - & $21(95)$ \\
Other $(\%)$ & $3(7)$ & $2(10)$ & $1(5)$ \\
\hline
\end{tabular}

Median (IQR) for age and BMI. BMI: body mass index.

\section{Inflammatory response}

CRP and PCT increased on POD 2: $\triangle \max 29 \pm 5$ $\mathrm{mg} / \mathrm{L}(\mathrm{p}<0.001)$ and $\Delta \max 0.05 \pm 0.01 \mu \mathrm{g} / \mathrm{L}(\mathrm{p}=0.005)$, respectively. Leucocytes increased at POD 1: $\Delta \max$ 2.2 $\pm 0.3 \mathrm{G} / \mathrm{L}(\mathrm{p}<0.001)$. Albumin decreased at POD 2: $\Delta \max -6.0 \pm 0.5 \mathrm{~g} / \mathrm{L}(\mathrm{p}<0.001)$.

The profiles of inflammatory markers displayed by chemotherapy regimen are illustrated in Figure 3. For both regimens CRP and Lc count were characterized by an increase on POD 2 and POD 1 respectively (Figures 3A and 3C). Conversely, albumin level decreased by POD 2 (Figures 3D). Both regimens influenced markers' kinetics similarly except for PCT (where oxaliplatin induced a higher increase than cisplatin+doxorubicin) (Figure 3C).

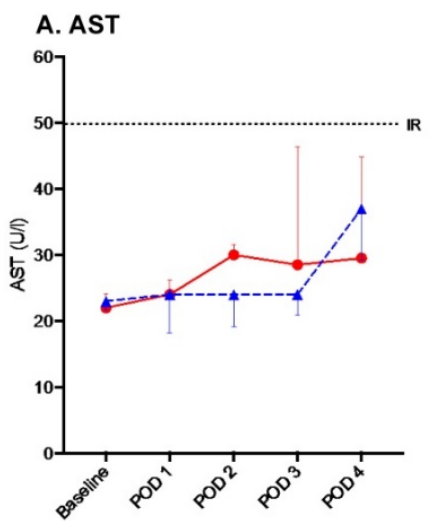

Ox vs. Cis + Doxo: $p=0.251$

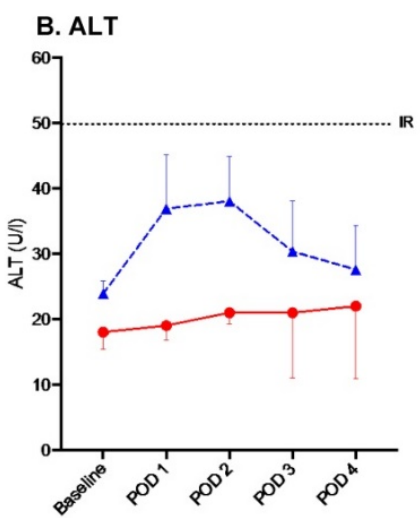

Ox vs. Cis + Doxo: $p=0.288$

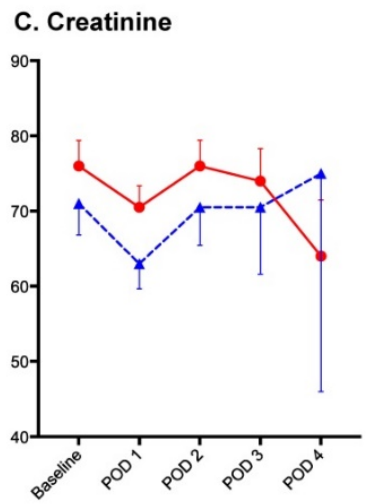

Ox vs. Cis + Doxo: $p=0.371$

Figure 1. Hepato-renal toxicity after Pressurized Intraperitoneal Aerosol Chemotherapy (PIPAC) treatment by chemotherapy regimen (Oxaliplatin vs. Cisplatin and Doxorubicin) Oxaliplatin, $\Delta$ Cisplatin + Doxorubicin, Bars represent standard error of the mean (SEM), IR (Institutional Reference, U/L) Hepato-renal toxicity after PIPAC treatment by chemotherapy regimen until postoperative day (POD) 4. AST - aspartate aminotransferase, ALT alanine aminotransferase. 
A. AST

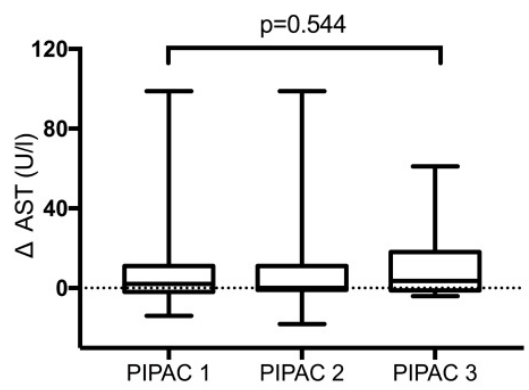

B. ALT

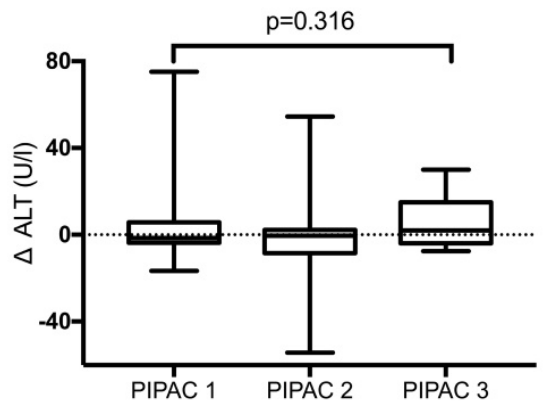

C. Creatinine

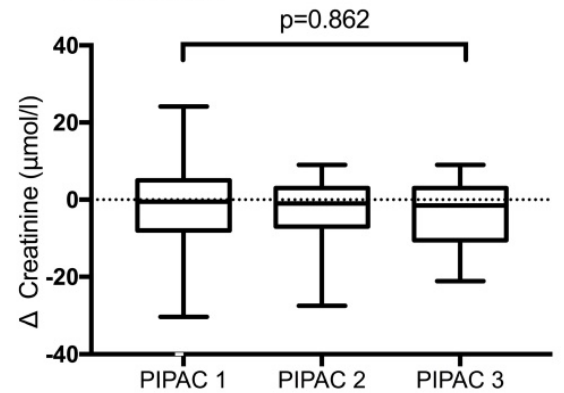

Figure 2. Hepato-renal toxicity after repetitive Pressurized Intraperitoneal Aerosol Chemotherapy (PIPAC) procedures. Hepato-renal toxicity under PIPAC treatment represented by AST, ALT and Creatinine levels. $\Delta$ represents $\Delta$ max. No significant difference $(P<0.05)$ was found for repetitive PIPAC applications. AST - aspartate aminotransferase, ALT - alanine aminotransferase.

\section{A. C-reactive protein}

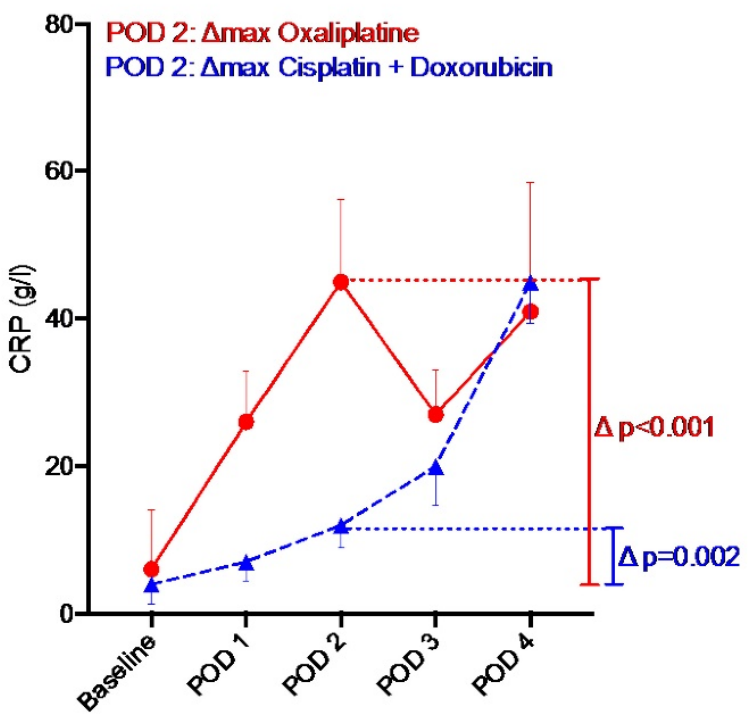

C. Leukocytes

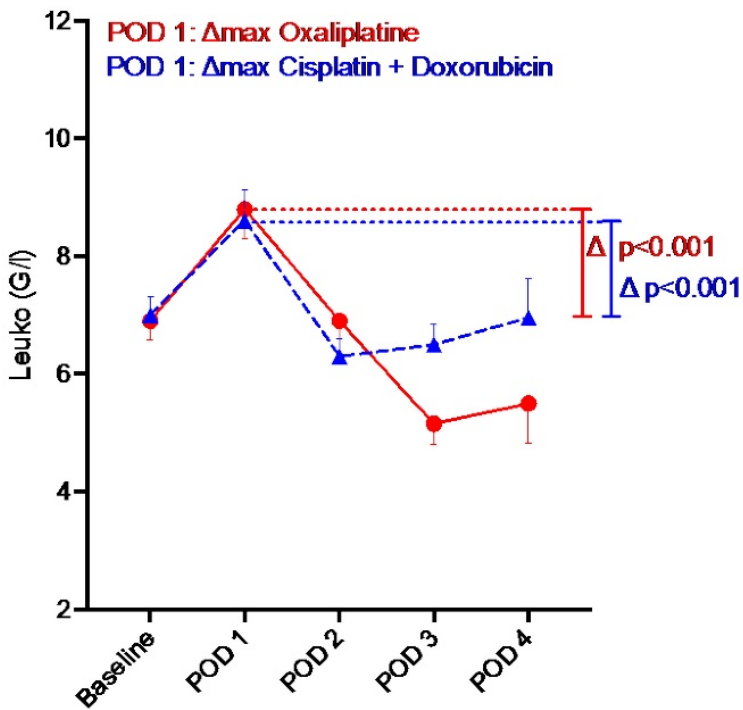

\section{B. Procalcitonin}

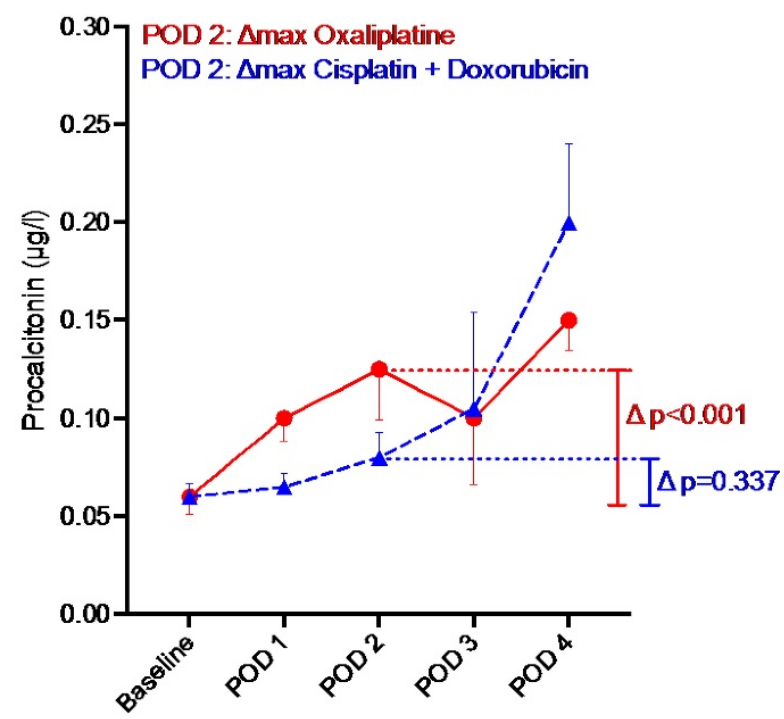

D. Albumin

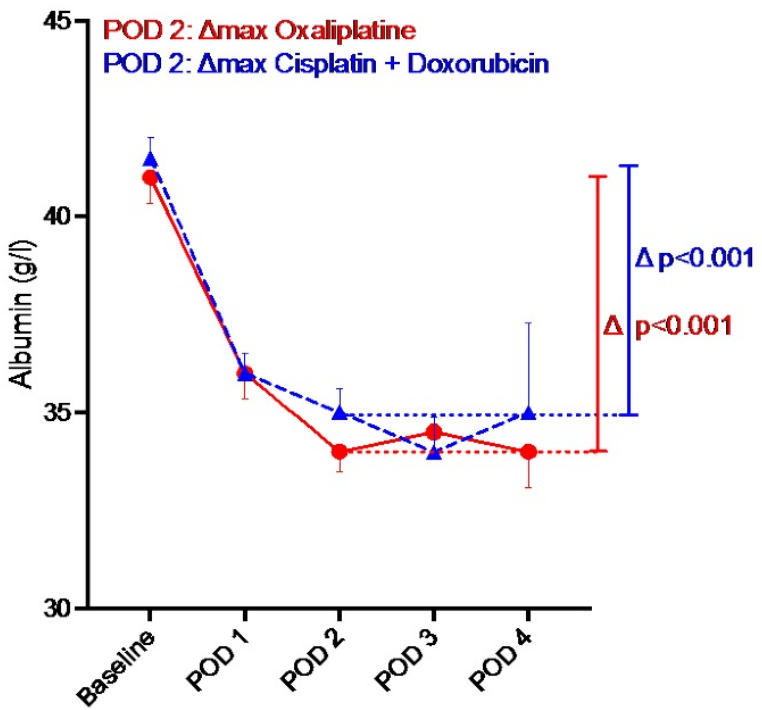

Figure 3. Inflammatory response after Pressurized Intraperitoneal Aerosol Chemotherapy (PIPAC) by chemotherapy regimen. Oxaliplatin $\Delta$ Cisplatin +Doxorubicin. Inflammatory response under PIPAC treatment by chemotherapy regimen until postoperative day (POD) 4. Bars represent standard error of the mean (SEM). 


\section{A. C-reactive protein POD 2}

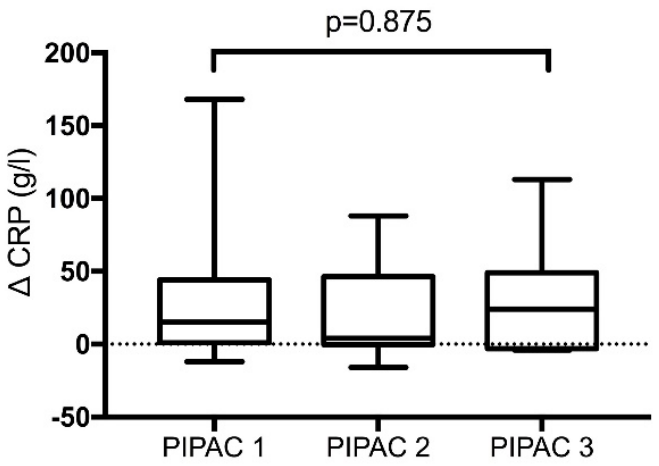

\section{Leukocytes} POD 1

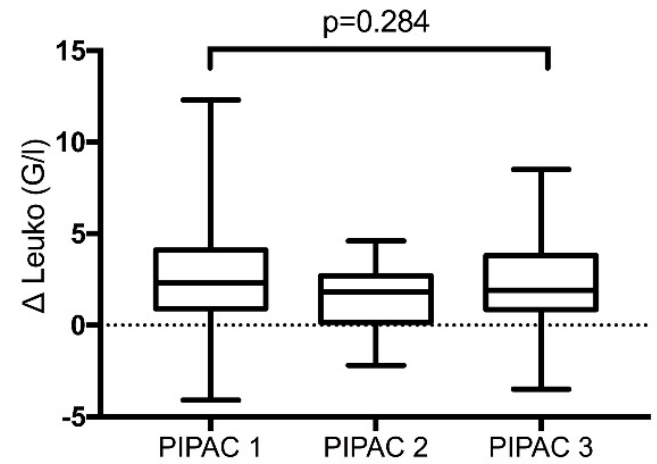

\section{B. Procalcitonin} POD 2

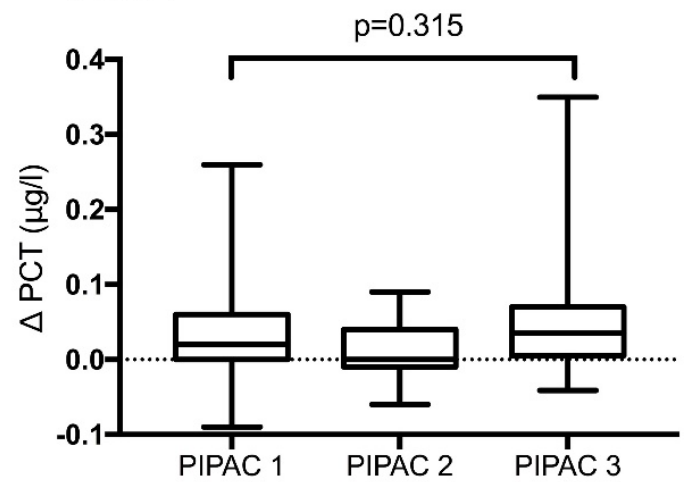

\section{Albumin} POD 2

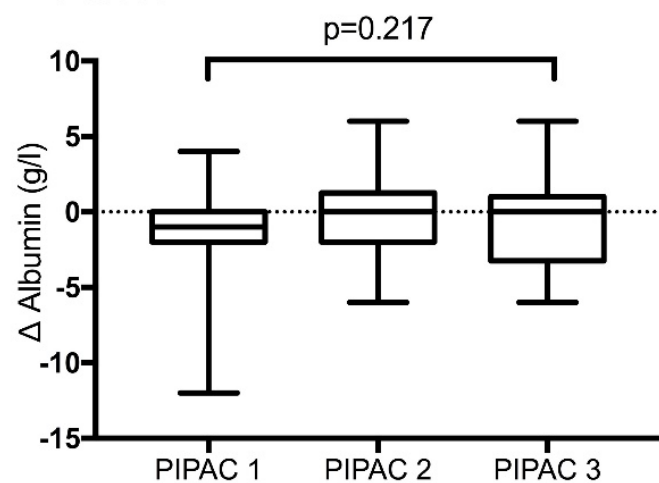

Figure 4. Inflammatory response after repetitive Pressurized Intraperitoneal Aerosol Chemotherapy (PIPAC) procedures. Inflammatory response under PIPAC treatment represented by C-reactive protein at post-operative day (POD) 2, Procalcitonin at POD 2, Leukocytes at POD 1 and Albumin at POD 2. Bars represent standard error of the mean (SEM). $\Delta$ represents $\triangle$ max.No significant difference was found when inflammatory response was compared before and after different PIPAC applications.

Of note, one patient $(2 \%)$ presented leukopenia after PIPAC 1 with spontaneous resolution within 2 days. One patient had fever $>38^{\circ}$ after PIPAC \#3 also with spontaneous resolution.

In 17 patients $(40 \%)$, relevant postoperative inflammation as defined under methods was observed. Ten patients $(24 \%)$ showed increased Lc count above 12G/L, 2 patients (5\%) increased CRP level above $140 \mathrm{~g} / \mathrm{L}$ and 3 patients (7\%) PCT level above 0.25 $\mu \mathrm{g} / \mathrm{L}$. Only one patient (2\%) had concomitant relevant increase of Lc and CRP levels and another patient (2\%) of Lc and PCT levels.

The extent of inflammatory response after consecutive PIPAC procedures was similar with no significant difference for any of the candidate markers (Figure 4).

Using CRP and PCI as respective surrogate markers of inflammation and tumor burden, the inflammatory response induced by PIPAC correlated positively with tumor load $(\rho=0.521, \mathrm{p}>0.001)$ (Figure $5)$.

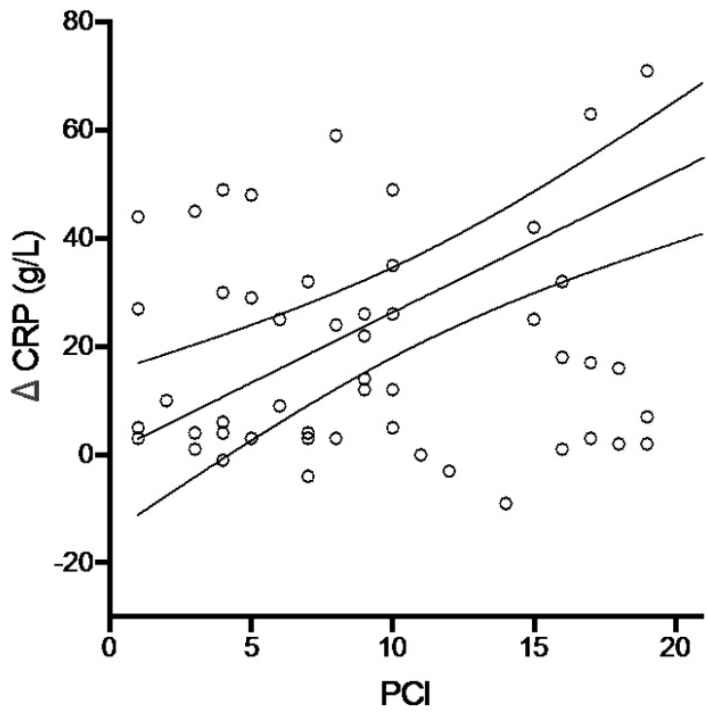

$$
\rho=0.521: p>0.001
$$

Figure 5. Tumor load and post- Pressurized Intraperitoneal Aerosol Chemotherapy (PIPAC) inflammation. C-reactive protein (CRP) was plotted against the extent of peritoneal disease (measured by the Peritoneal Cancer Index (PCI)). 
Table 2. Synopsis of systemic toxicity and inflammation after different treatments for peritoneal carcinomatosis

\begin{tabular}{|c|c|c|c|c|c|c|}
\hline & $\begin{array}{l}\text { Toxicity } \\
\text { Renal }\end{array}$ & Hepatic & Hematologic & Other & $\begin{array}{l}\text { Inflammatory } \\
\text { Reaction }\end{array}$ & $\begin{array}{l}\text { Drug } \\
\text { Concentration }\end{array}$ \\
\hline $\begin{array}{l}\text { Systemic } \\
\text { chemo }\end{array}$ & $\begin{array}{l}\text { Creatinin } \\
\text { increase:5-10\%* }\end{array}$ & $\begin{array}{l}\text { AST / ALT increase: } \\
36-54 \% *\end{array}$ & $\begin{array}{l}\text { Neutropenia: } 42 \% \text { [40] } \\
\text { Thrombopenia: 3-4\% } \\
\text { [41] (III-IV) }\end{array}$ & $\begin{array}{l}\text { Neurotoxicity } \\
\text { up to } 90 \% \text { [42] } \\
\text { (dose-dependent) }\end{array}$ & Fever 25\% [40] & $\begin{array}{l}\text { Oxaliplatin: } \\
85 \mathrm{mg} / \mathrm{m}^{2}\end{array}$ \\
\hline HIPEC & $\begin{array}{l}\text { Creatinin increase: } \\
18 \% \text { [43] } \\
\text { Nephro-toxicity: } \\
6 \%[43] \\
(\text { III-V)* }\end{array}$ & $\begin{array}{l}\text { Hepato-toxicity }{ }^{* *} \\
36 \% \text { (III) } 50 \% \text { (II) [44] }\end{array}$ & $\begin{array}{l}\text { Neutropenia: } 27 \%[45]^{* *} \\
40 \%[46]^{* * *}\end{array}$ & $\begin{array}{l}\text { Surgical morbidity: } \\
34 \% \text { (III }+\mathrm{IV} \text { ) } \\
4 \% \text { mortality [5] }\end{array}$ & $\begin{array}{l}\text { CRP at } 48 \mathrm{~h}: 180 \mathrm{mg} / \mathrm{L} \\
\text { [47] }\end{array}$ & $\begin{array}{l}\text { *Cisplatin } \\
75 \mathrm{mg} / \mathrm{m}^{2} \\
+/- \text { Mitomycin-C } \\
10 \mathrm{mg} / \mathrm{m}^{2} \\
{ }^{* *} \text { Oxaliplatin } \\
460 \mathrm{mg} / \mathrm{m}^{2} \\
{ }^{* * *} \mathrm{Mitomycin}-\mathrm{C} 0.8 \\
\mathrm{mg} / \mathrm{kg}\end{array}$ \\
\hline IP catheter & $\begin{array}{l}\text { Nephro-toxicity } \\
7 \%[32] \\
\text { (III-IV) }\end{array}$ & $\begin{array}{l}\text { Hepato-toxicity } \\
3 \%[32] \\
\text { (III-IV) }\end{array}$ & $\begin{array}{l}\text { Leukopenia: } \\
\text { 40-76\% [32, 33] } \\
\text { Thrombopenia: 8-12\% } \\
{[32,33]} \\
\text { Anemia: } 26 \%[33]\end{array}$ & $\begin{array}{l}\text { Neurologic events: } \\
19 \% \text { [32] (III-IV) }\end{array}$ & $\begin{array}{l}\text { Infection: } 16 \% \text { [32] } \\
\text { (III-IV) }\end{array}$ & $\begin{array}{l}\text { Cisplatin } \\
100 \mathrm{mg} / \mathrm{m}^{2}+/- \\
\text { Paclitaxel } \\
60 \mathrm{mg} / \mathrm{m}^{2}\end{array}$ \\
\hline PIPAC & None & $\begin{array}{l}\text { TransitorygGT increase } \\
{[36]} \\
\text { AST/ALT increase: } \\
14-16 \%\end{array}$ & None & $\begin{array}{l}\text { Surgical morbidity: } \\
9 \% \text { (mainly I+II) [8] }\end{array}$ & $\begin{array}{l}\text { CRP at } 48 \mathrm{~h}: \\
45 \mathrm{mg} / \mathrm{L}^{*} \\
\mathrm{CRP} \text { at } 48 \mathrm{~h} \\
15 \mathrm{mg} / \mathrm{L}^{* *}\end{array}$ & $\begin{array}{l}\text { *Oxaliplatin } \\
92 \mathrm{mg} / \mathrm{m}^{2} \\
{ }^{* *} \text { Cisplatin } \\
7.5 \mathrm{mg} / \mathrm{m}^{2}+ \\
\text { Doxorubicin } \\
1.5 \mathrm{mg} / \mathrm{m}^{2}\end{array}$ \\
\hline
\end{tabular}

Chemo - chemotherapy, HIPEC - Hyperthermic Intraperitoneal Chemotherapy, IP - intraperitoneal, PIPAC - Pressurized Intraperitoneal Aerosol Chemotherapy, AST aspartate aminotransferase, ALT - alanine aminotransferase, CRP - C-Reactive Protein, gGT - gamma Glutamyltransferase Severity grades of complications are displayed in brackets.

\section{Discussion}

In this cohort, PIPAC was followed by a modest and transitory inflammatory response that was commensurate to the disease extent. No hematological, renal or hepatic toxicity was observed even after repetitive administration.

The findings of the present study need to be discussed in the setting of four available treatment options for advanced peritoneal carcinomatosis: systemic chemotherapy, hyperthermic intraperitoneal chemotherapy (HIPEC) after cytoreductive surgery (CRS), intraperitoneal catheter chemotherapy and PIPAC (Table 2). Of note, it is not the intention to formally compare those treatment approaches due to their very different nature but to provide a comprehensive overview on what is known on toxicity and inflammatory response under the respective treatment.

Systemic chemotherapy represents a first line therapy in patients with peritoneal carcinomatosis, especially with extraperitoneal spread of tumor [20]. New drugs such as antibodies or irinotecan allowed for better survival in recent years, but pharmacokinetic limitations such as peritoneumplasma barrier impede proper penetration of cytostatics in peritoneal tumor nodes [21, 22]. Parenteral drug concentrations need thus to be high to achieve a therapeutic effect. Up to tenfold higher concentrations were described for systemic chemotherapy as compared to intraperitoneal use, and side effects for most therapies are common [4]. Chemotherapy induced peripheral neuropathy represents a well-known side effect of platin-based chemotherapy regimens [23]. Up to $90 \%$ of patients are affected after systemic oxaliplatin treatment, and treatment options remain scarce [24, 25]. Cisplatin is eliminated by the kidney, and dose-dependent renal toxicity of cisplatin and its metabolites has been described [26]. Standard systemic doses of 75-100 $\mathrm{mg} / \mathrm{m}^{2}$ lead to tubular necrosis in up to $30 \%$ of patients, and renal failure might be the ultimate consequence [26]. Taken together and in the light of pharmacokinetic limitations of systemic therapy for the treatment of peritoneal carcinomatosis, alternative locoregional treatments were considered.

Cytoreductive surgery combined with HIPEC represents the only potentially curative treatment option in few selected patients who are fit enough to tolerate this complex treatment option with important morbi-mortality [5, 27]. Intraperitoneal administration permits higher drug concentration with better tumor penetration as compared to systemic chemotherapy $[28,29]$. Even if no formal consensus exists, common drugs for HIPEC are cisplatin, mitomycin $C$ and oxaliplatin in different combinations and doses, depending on the primary tumor [27]. In high volume centers, mortality rates of up to $5.8 \%$, major complication rates between $12-52 \%$ and hematological toxicity of up to $28 \%$ of patients were described using 
these regimens [27]. Irinotecan was added in more recent years; neutropenia and thrombopenia at the $7^{\text {th }}$ postoperative day occurred in $11 \%$ of patients in a cohort treated with a combination of Irinotecan and Oxaliplatin [30]. In a recent study using the same regimen, hematologic toxicity was even higher with $41 \%$ neutropenic $(<500 / \mu \mathrm{l})$ patients and $26 \%$ with grade 3 thrombopenia $(<50000 / \mu \mathrm{l})$ [31]. PIPAC as a minimally invasive treatment option might thus represent an alternative for frail patients who are not eligible for this curative approach given the multitude of surgery- and drug-related side effects.

Repetitive administration through intraperitoneal catheters in an adjuvant setting after optimally debulked stage III ovarian cancer represents an alternative to HIPEC [32]. Intraperitoneal administration of paclitaxel and cisplatin combined with intravenous paclitaxel significantly improved survival compared to patients receiving the same drugs exclusively intravenously [32]. However, patients in the intraperitoneal group experienced more pain and presented more hematologic, gastrointestinal and neurologic toxic effects (Table 2). A former study compared intraperitoneal cisplatin to intravenous cisplatin to demonstrate improved survival and fewer toxic effects in the intraperitoneal group [33].

PIPAC combines the advantages of intraperitoneal administration, allowing for higher tumor concentrations [28] and administration under pressure, which permits higher intra-tumoral concentrations despite lower drug doses [3]. In a pilot study of the pioneer group from Herne, Germany, peripheral drug concentrations of doxorubicin were very low with $4.0-6.2 \mathrm{ng} / \mathrm{ml}$ after PIPAC treatment within standard conditions [1]. As a consequence, only modest and transitory inflammatory response was observed in former studies and in the present cohort [34-36]. This response might be a consequence of drug-induced chemical peritonitis after intraperitoneal vaporisation, which provides an explanation for abdominal pain as main postoperative complaint after PIPAC [34]. Two centers reported on toxicological aspects of PIPAC treatment [35, 36]. Similar to the present findings, Blanco described liver and renal parameters within the normal range with no cumulative toxicity [35]. Similarly, an Italian group described no clinically relevant liver cytolysis without metabolic nor synthetic hepatic and renal dysfunction [36]. Both groups concluded that PIPAC caused less hepatic and renal toxicity than other chemotherapy delivery routes due to lower therapeutic doses and favorable kinetics $[35,36]$. The present findings confirm the previously reported results. As a consequence of low toxicity, encouraging results regarding quality of life and tolerance of the procedure have been described by our group and by others $[8,9,37]$.

Several limitations of the present study need to be discussed beyond retrospective study design and small patient cohort. Given the very short median hospital stay, only few patients were available for blood drawings after POD 3 and inflammatory parameters beyond POD 3 should therefore not be considered representative for the entire PIPAC cohort. Systemic toxicity was low in the present study, which might be due to low administered drug concentrations. The proposed regimens did not derive from a dose escalation protocol and hence, drug choices and doses rely on empirical protocols. Three dose escalation studies however have been initiated in the meantime (NCT02475772, NCT03172416 and Eudra-CT 2016-003666-49). Since PIPAC is a very new technique, no long-term results are available to date. Despite favorable short-term results regarding clinical and histological response rates [34, 38, 39], sustained long-term impact of PIPAC under presently applied conditions needs yet to be proven.

In conclusion, there was no relevant systemic toxicity after PIPAC with the current treatment standard even when repeatedly applied. Inflammatory response was modest and transitory. It is important to repeat this type of studies for new treatment standards, especially when using higher drug concentrations.

\section{Competing Interests}

The authors have declared that no competing interest exists.

\section{References}

1. Solass W, Kerb R, Murdter T, Giger-Pabst U, Strumberg D, Tempfer C, Zieren J, Schwab M, Reymond MA: Intraperitoneal chemotherapy of peritoneal carcinomatosis using pressurized aerosol as an alternative to liquid solution: first evidence for efficacy. Annals of surgical oncology 2014, 21(2):553-559.

2. Solass W, Hetzel A, Nadiradze G, Sagynaliev E, Reymond MA: Description of a novel approach for intraperitoneal drug delivery and the related device. Surgical endoscopy 2012, 26(7):1849-1855.

3. Facy O, Al Samman S, Magnin G, Ghiringhelli F, Ladoire S, Chauffert B, Rat P, Ortega-Deballon P: High pressure enhances the effect of hyperthermia in intraperitoneal chemotherapy with oxaliplatin: an experimental study. Annals of surgery 2012, 256(6):1084-1088.

4. Esquis P, Consolo D, Magnin G, Pointaire P, Moretto P, Ynsa MD, Beltramo JL, Drogoul C, Simonet M, Benoit L et al: High intra-abdominal pressure enhances the penetration and antitumor effect of intraperitoneal cisplatin on experimental peritoneal carcinomatosis. Annals of surgery 2006, 244(1):106-112.

5. Glehen O, Gilly FN, Boutitie F, Bereder JM, Quenet F, Sideris L, Mansvelt B, Lorimier G, Msika S, Elias D et al: Toward curative treatment of peritoneal carcinomatosis from nonovarian origin by cytoreductive surgery combined with perioperative intraperitoneal chemotherapy: a multi-institutional study of 1,290 patients. Cancer 2010, 116(24):5608-5618.

6. Verwaal VJ: Long-term results of cytoreduction and HIPEC followed by systemic chemotherapy. Cancer journal 2009, 15(3):212-215.

7. Ceelen WP, Pahlman L, Mahteme H: Pharmacodynamic aspects of intraperitoneal cytotoxic therapy. Cancer Treat Res 2007, 134:195-214.

8. Hubner M, Teixeira Farinha H, Grass F, Wolfer A, Mathevet P, Hahnloser D, Demartines N: Feasibility and Safety of Pressurized Intraperitoneal Aerosol Chemotherapy for Peritoneal Carcinomatosis: A Retrospective Cohort Study. Gastroenterol Res Pract 2017, 2017:6852749.

9. Teixeira Farinha H, Grass F, Kefleyesus A, Achtari C, Romain B, Montemurro M, Demartines N, Hubner M: Impact of Pressurized Intraperitoneal Aerosol Chemotherapy on Quality of Life and Symptoms in Patients with Peritoneal 
Carcinomatosis: A Retrospective Cohort Study. Gastroenterol Res Pract 2017, 2017:4596176

10. Vandenbroucke JP, von Elm E, Altman DG, Gotzsche PC, Mulrow CD, Pocock SJ, Poole C, Schlesselman JJ, Egger M, Initiative S: Strengthening the Reporting of Observational Studies in Epidemiology (STROBE): explanation and elaboration. Epidemiology 2007, 18(6):805-835.

11. Solass W, Giger-Pabst U, Zieren J, Reymond MA: Pressurized intraperitoneal aerosol chemotherapy (PIPAC): occupational health and safety aspects. Annals of surgical oncology 2013, 20(11):3504-3511.

12. Hubner M, Grass F, Teixeira-Farinha H, Pache B, Mathevet P, Demartines N: Pressurized IntraPeritoneal Aerosol Chemotherapy - Practical aspects. European journal of surgical oncology: the journal of the European Society of Surgical Oncology and the British Association of Surgical Oncology 2017, 43(6):1102-1109.

13. Kellum JA, Levin N, Bouman C, Lameire N: Developing a consensus classification system for acute renal failure. Curr Opin Crit Care 2002, 8(6):509-514

14. Bellomo R, Ronco C, Kellum JA, Mehta RL, Palevsky P, Acute Dialysis Quality Initiative w: Acute renal failure - definition, outcome measures, animal models, fluid therapy and information technology needs: the Second International Consensus Conference of the Acute Dialysis Quality Initiative (ADQI) Group. Critical care 2004, 8(4):R204-212.

15. Meisner M: Update on procalcitonin measurements. Ann Lab Med 2014, 34(4):263-273.

16. Almeida AB, Faria G, Moreira H, Pinto-de-Sousa J, Correia-da-Silva P, Maia JC: Elevated serum $\mathrm{C}$-reactive protein as a predictive factor for anastomotic leakage in colorectal surgery. Int J Surg 2012, 10(2):87-91.

17. Pedersen $\mathrm{T}$, Roikjaer $\mathrm{O}$, Jess $\mathrm{P}$ : Increased levels of $\mathrm{C}$-reactive protein and leukocyte count are poor predictors of anastomotic leakage following laparoscopic colorectal resection. Dan Med J 2012, 59(12):A4552.

18. Hubner M, Mantziari S, Demartines N, Pralong F, Coti-Bertrand P, Schafer M: Postoperative Albumin Drop Is a Marker for Surgical Stress and a Predictor for Clinical Outcome: A Pilot Study. Gastroenterol Res Pract 2016, 2016:8743187.

19. Oken MM, Creech RH, Tormey DC, Horton J, Davis TE, McFadden ET, Carbone PP: Toxicity and response criteria of the Eastern Cooperative Oncology Group. Am J Clin Oncol 1982, 5(6):649-655.

20. Franko J, Shi Q, Goldman CD, Pockaj BA, Nelson GD, Goldberg RM, Pitot HC, Grothey A, Alberts SR, Sargent DJ: Treatment of colorectal peritoneal carcinomatosis with systemic chemotherapy: a pooled analysis of north central cancer treatment group phase III trials N9741 and N9841. Journal of clinical oncology: official journal of the American Society of Clinical Oncology 2012, 30(3):263-267.

21. Franko J, Ibrahim Z, Gusani NJ, Holtzman MP, Bartlett DL, Zeh HJ, 3rd: Cytoreductive surgery and hyperthermic intraperitoneal chemoperfusion versus systemic chemotherapy alone for colorectal peritoneal carcinomatosis. Cancer 2010, 116(16):3756-3762.

22. Flessner MF: The transport barrier in intraperitoneal therapy. Am J Physiol Renal Physiol 2005, 288(3):F433-442.

23. Poupon L, Kerckhove N, Vein J, Lamoine S, Authier N, Busserolles J, Balayssac D: Minimizing chemotherapy-induced peripheral neuropathy: preclinical and clinical development of new perspectives. Expert Opin Drug Saf 2015, 14(8):1269-1282.

24. Hershman DL, Lacchetti C, Dworkin RH, Lavoie Smith EM, Bleeker J, Cavaletti G, Chauhan C, Gavin P, Lavino A, Lustberg MB et al: Prevention and management of chemotherapy-induced peripheral neuropathy in survivors of adult cancers: American Society of Clinical Oncology clinical practice guideline. Journal of clinical oncology: official journal of the American Society of Clinical Oncology 2014, 32(18):1941-1967.

25. Balayssac D, Ferrier J, Descoeur J, Ling B, Pezet D, Eschalier A, Authier N: Chemotherapy-induced peripheral neuropathies: from clinical relevance to preclinical evidence. Expert Opin Drug Saf 2011, 10(3):407-417.

26. dos Santos NA, Carvalho Rodrigues MA, Martins NM, dos Santos AC: Cisplatin-induced nephrotoxicity and targets of nephroprotection: an update. Arch Toxicol 2012, 86(8):1233-1250.

27. Chua TC, Yan TD, Saxena A, Morris DL: Should the treatment of peritoneal carcinomatosis by cytoreductive surgery and hyperthermic intraperitoneal chemotherapy still be regarded as a highly morbid procedure? a systematic review of morbidity and mortality. Annals of surgery 2009, 249(6):900-907.

28. Solass W, Herbette A, Schwarz T, Hetzel A, Sun JS, Dutreix M, Reymond MA: Therapeutic approach of human peritoneal carcinomatosis with Dbait in combination with capnoperitoneum: proof of concept. Surgical endoscopy 2012, 26(3):847-852.

29. Ceelen WP, Hesse U, de Hemptinne B, Pattyn P: Hyperthermic intraperitoneal chemoperfusion in the treatment of locally advanced intra-abdominal cancer. Br J Surg 2000, 87(8):1006-1015.

30. Elias D, Goere D, Blot F, Billard V, Pocard M, Kohneh-Shahri N, Raynard B: Optimization of hyperthermic intraperitoneal chemotherapy with oxaliplatin plus irinotecan at 43 degrees $C$ after compete cytoreductive surgery: mortality and morbidity in 106 consecutive patients. Annals of surgical oncology 2007, 14(6):1818-1824

31. Quenet F, Goere D, Mehta SS, Roca L, Dumont F, Hessissen M, Saint-Aubert B, Elias D: Results of two bi-institutional prospective studies using intraperitoneal oxaliplatin with or without irinotecan during HIPEC after cytoreductive surgery for colorectal carcinomatosis. Annals of surgery 2011, 254(2):294-301
32. Armstrong DK, Bundy B, Wenzel L, Huang HQ, Baergen R, Lele S, Copeland LJ, Walker JL, Burger RA, Gynecologic Oncology G: Intraperitoneal cisplatin and paclitaxel in ovarian cancer. N Engl J Med 2006, 354(1):34-43.

33. Alberts DS, Liu PY, Hannigan EV, O'Toole R, Williams SD, Young JA, Franklin EW, Clarke-Pearson DL, Malviya VK, DuBeshter B: Intraperitoneal cisplatin plus intravenous cyclophosphamide versus intravenous cisplatin plus intravenous cyclophosphamide for stage III ovarian cancer. N Engl J Med 1996, 335(26):1950-1955.

34. Tempfer CB, Winnekendonk G, Solass W, Horvat R, Giger-Pabst U, Zieren J, Rezniczek GA, Reymond MA: Pressurized intraperitoneal aerosol chemotherapy in women with recurrent ovarian cancer: A phase 2 study. Gynecologic oncology 2015, 137(2):223-228.

35. Blanco A, Giger-Pabst U, Solass W, Zieren J, Reymond MA: Renal and hepatic toxicities after pressurized intraperitoneal aerosol chemotherapy (PIPAC). Annals of surgical oncology 2013, 20(7):2311-2316.

36. Robella M, Vaira M, De Simone M: Safety and feasibility of pressurized intraperitoneal aerosol chemotherapy (PIPAC) associated with systemic chemotherapy: an innovative approach to treat peritoneal carcinomatosis. World journal of surgical oncology 2016, 14:128.

37. Odendahl K, Solass W, Demtroder C, Giger-Pabst U, Zieren J, Tempfer C, Reymond MA: Quality of life of patients with end-stage peritoneal metastasis treated with Pressurized IntraPeritoneal Aerosol Chemotherapy (PIPAC). European journal of surgical oncology: the journal of the European Society of Surgical Oncology and the British Association of Surgical Oncology 2015, 41(10):1379-1385.

38. Nadiradze G, Giger-Pabst U, Zieren J, Strumberg D, Solass W, Reymond MA: Pressurized Intraperitoneal Aerosol Chemotherapy (PIPAC) with Low-Dose Cisplatin and Doxorubicin in Gastric Peritoneal Metastasis. Journal of gastrointestinal surgery: official journal of the Society for Surgery of the Alimentary Tract 2016, 20(2):367-373.

39. Demtroder C, Solass W, Zieren J, Strumberg D, Giger-Pabst U, Reymond MA: Pressurized intraperitoneal aerosol chemotherapy with oxaliplatin in colorectal peritoneal metastasis. Colorectal disease: the official journal of the Association of Coloproctology of Great Britain and Ireland 2016, 18(4):364-371.

40. Haller DG: Safety of oxaliplatin in the treatment of colorectal cancer. Oncology (Williston Park) 2000, 14(12 Suppl 11):15-20.

41. Jardim DL, Rodrigues CA, Novis YA, Rocha VG, Hoff PM: Oxaliplatin-related thrombocytopenia. Annals of oncology: official journal of the European Society for Medical Oncology 2012, 23(8):1937-1942.

42. Pachman DR, Qin R, Seisler DK, Smith EM, Beutler AS, Ta LE, Lafky JM, Wagner-Johnston ND, Ruddy KJ, Dakhil S et al: Clinical Course of Oxaliplatin-Induced Neuropathy: Results From the Randomized Phase III Trial N08CB (Alliance). Journal of clinical oncology: official journal of the American Society of Clinical Oncology 2015, 33(30):3416-3422.

43. Canda AE, Sokmen S, Terzi C, Arslan C, Oztop I, Karabulut B, Ozzeybek D, Sarioglu S, Fuzun M: Complications and toxicities after cytoreductive surgery and hyperthermic intraperitoneal chemotherapy. Annals of surgical oncology 2013, 20(4):1082-1087.

44. Ceelen WP, Peeters M, Houtmeyers P, Breusegem C, De Somer F, Pattyn P: Safety and efficacy of hyperthermic intraperitoneal chemoperfusion with high-dose oxaliplatin in patients with peritoneal carcinomatosis. Annals of surgical oncology 2008, 15(2):535-541.

45. Hompes D, D'Hoore A, Wolthuis A, Fieuws S, Mirck B, Bruin S, Verwaal V: The use of Oxaliplatin or Mitomycin C in HIPEC treatment for peritoneal carcinomatosis from colorectal cancer: a comparative study. Journal of surgical oncology 2014, 109(6):527-532.

46. Kemmel V, Mercoli HA, Meyer N, Brumaru D, Romain B, Lessinger JM, Brigand C: Mitomycin C Pharmacokinetics as Predictor of Severe Neutropenia in Hyperthermic Intraperitoneal Therapy. Annals of surgical oncology 2015, 22 Suppl 3:S873-879.

47. Medina Fernandez FJ, Munoz-Casares FC, Arjona-Sanchez A, Casado-Adam A, Gomez-Luque I, Garcilazo Arismendi DJ, Thoelecke H, Rufian Pena S, Briceno Delgado J: Postoperative time course and utility of inflammatory markers in patients with ovarian peritoneal carcinomatosis treated with neoadjuvant chemotherapy, cytoreductive surgery, and HIPEC. Annals of surgical oncology 2015, 22(4):1332-1340. 